\title{
Pneumocystis pneumonia in South African children diagnosed by molecular methods
}

\author{
Brenda M Morrow ${ }^{1 *}$, Catherine M Samuel ${ }^{2}$, Marco Zampoli ${ }^{1}$, Andrew Whitelaw ${ }^{2}$ and Heather J Zar ${ }^{1}$
}

\begin{abstract}
Background: Pneumocystis pneumonia (PCP) is an important cause of hospitalization and mortality in HIV-infected children. However, the incidence of PCP has been underestimated due to poor sensitivity of diagnostic tests. The use of polymerase chain reaction (PCR) for pneumocystis has enabled more reliable diagnosis. This study describes the incidence, clinical features and outcome of PCP in South African children diagnosed using PCR.

Methods: A prospective study of children hospitalised in South Africa with suspected PCP was done from November 2006 to August 2008. Clinical, laboratory and radiological information were collected. Lower respiratory tract specimens were obtained for PCP immunofluorescence (IF), real- time PCR for pneumocystis, bacterial and mycobacterial culture. Nasopharyngeal aspirates were taken for immunofluorescence (IF), real-time PCR for pneumocystis and PCR for respiratory viruses. A blood specimen for bacterial culture and for cytomegalovirus PCR was taken. Children were followed for the duration of their hospitalisation and the outcome was recorded.

Results: 202 children [median (interquartile range, IQR) age 3.2 (2.1 - 4.6) months] were enrolled; 124 (61.4\%) were HIV infected. PCP was identified in 109 (54\%) children using PCR, compared to 43 (21\%) using IF and Grocott staining ( $p<0.0001)$. Most PCP cases (88, 81\%) occurred in HIV-infected children. All 21 cases (19\%) occurring in HIV- negative children had another risk factor for PCP. On logistic regression, predictive factors for PCP were HIV infection, lack of fever, high respiratory rate and low oxygen saturation whilst cotrimoxazole prophylaxis was protective (OR 0.24; $95 \%$ $\mathrm{Cl} 0.1$ to $0.5 ; p<0.002)$. The case fatality of children with PCP was higher than those without PCP $(32.1 \%$ versus $17.2 \%$; relative risk 1.87; 95\% confidence interval (Cl) 1.11 - 3.15). Amongst HIV-infected children, a CD4 less than 15\% was the only independent predictor of mortality.

Conclusions: The diagnostic yield for PCP is more than 2.5 times higher on PCR than other detection methods. PCP is a very common cause of severe hypoxic pneumonia and is associated with high mortality in HIV-infected African infants.
\end{abstract}

Keywords: Pneumocystis pneumonia, HIV, Children, Prophylaxis, PCR, Diagnosis, Incidence

\section{Background}

Pneumocystis pneumonia (PCP) is a major cause of morbidity and mortality in HIV infected infants [1-5]. Approximately $29-67 \%$ of respiratory related deaths among African HIV infected children have been associated with PCP [6-8], and in-hospital case-fatality rates range from $20-63 \%$ [1,2,9-11]. South African studies have reported that the prevalence of PCP ranges from 10\% to $49 \%$ among antiretroviral naïve HIV infected children hospitalized with

\footnotetext{
*Correspondence: Brenda.morrow@uct.ac.za

'Department of Paediatics and Child Health, Red Cross War Memorial

Children's Hospital (RCWMCH), University of Cape Town, 5th Floor Institute of Child Health Building, Klipfontein Road, Rondebosch 7700, Cape Town, South Africa

Full list of author information is available at the end of the article
}

pneumonia [9-11]. PCP has also been shown to occur in HIV uninfected infants, mostly with an underlying predisposing factor such as HIV exposure or malnutrition [2,4,12-16].

The use of highly active antiretroviral therapy (HAART) has dramatically reduced the incidence of PCP in developed countries [17-19]. However PCP remains a common cause of hospitalization and mortality in HIV-infected South African children [2,4]. In a recent study, $21 \%$ of children admitted to a tertiary paediatric hospital with acute severe hypoxic pneumonia were found to have PCP despite a well- functioning paediatric HIV program [2]. In previous studies, immunofluorescence (IF) or silver staining of respiratory secretions have been used for the diagnosis of

\section{Biomed Central}


PCP. Such methods have been reported to be insensitive for diagnosis, potentially leading to under recognition of PCP [20-24].We recently reported that real-time polymerase chain reaction (PCR) is more sensitive than IF for the diagnosis of PCP when used on lower [induced sputum (IS) or non-bronchoscopic broncho-alveolar lavage (BAL)] or upper respiratory tract [nasopharyngeal aspirate (NPA)] specimens. The yield for PCP from upper and lower respiratory tract specimens was similar by PCR [20].

The aim of this study was to describe the incidence, clinical features and outcome of PCP in children when diagnosed with PCR.

\section{Methods}

This was a prospective study of consecutive children hospitalized for acute hypoxic pneumonia at Red Cross War Memorial Children's Hospital in Cape Town, South Africa from November 2006 to August 2008. Inclusion criteria were an acute onset of respiratory illness requiring hospitalization, defined as age specific tachypnoea, hypoxia and diffuse lung disease not associated with wheezing [2]. Children were excluded if they had received treatment for PCP in the preceding two weeks, if they had been on PCP therapy for the acute illness for more than 48 hours or if informed consent was not obtainable. The study was approved by the Research and Ethics Committee of the Faculty of Health Sciences at the University of Cape Town. Written informed consent for participation in the study was obtained from each child's parent or legal guardian.

Clinical, radiological and laboratory data were recorded including symptoms, signs and oxygen saturation. The HIV status of a child (if unknown) was confirmed using whole-blood HIV deoxyribonucleic acid PCR (Amplicor HIV-1 DNA test version 1.5, Roche Diagnostics, GmbH, Mannheim, Germany) in those younger than 18 months, or an HIV enzyme-linked immunosorbent assay (Architect HIV Ag/Ab Combo ELISA, Abbott Laboratories, Abbott Park, IL) in older children. CD4 counts and HIV viral loads were done in all children newly diagnosed with HIV and in those in whom HAART was commenced. A full blood count and serum lactate dehydrogenase (LDH) was done on admission.

An upper respiratory tract (NPA) and a lower respiratory tract (LRT) specimen (IS or BAL in intubated patients) were obtained in a standardized manner, as described previously $[25,26]$. Respiratory specimens were submitted for detection of $P$. jirovecii by direct IF using a monoclonal antibody (IF: Detect IF PC, Axis-Shield, UK) and Grocott staining. Real time PCR were done on stored histopathological specimens, as described by Samuel et al. [20].

Investigation for additional pathogens included "inhouse" respiratory viral shell vial culture and rapid viral antigen detection (murine FITC-conjugated anti- RSV or adenovirus monoclonal, Chemicon, Temecula, CA, USA) on respiratory specimens, bacterial blood culture and bacterial and mycobacterial culture on IS or BAL specimens. Blood specimens were also sent for qualitative whole blood nested cytomegalovirus (CMV) PCR (Super-Therm, JMR Holdings, Kent, UK). CMV pneumonia was defined as positive CMV PCR on a blood specimen as well as detection of CMV on a LRT sample.

Children received standard therapy including oxygen, broad spectrum antibiotics and intravenous cotrimoxazole (trimethoprim-sulfamethoxazole) and oral corticosteroids (prednisone $1-2 \mathrm{mg} / \mathrm{kg}$ with tapered doses for up to 21 days) as per national guidelines [27]. Eligible children were started on HAART according to national guidelines [28].

\section{Statistical analysis}

Continuous data were tested for normality using the Shapiro- Wilks test. Descriptive statistics, Mann- Whitney $\mathrm{U}$ tests for continuous data, and chi- square tests for categorical data (Yates- corrected chi-square tests where values in the cells were $<10$ ) were performed using STATISTICA data analysis software system (version 8, StatSoft, Inc. 2004). Forward stepwise logistic regression analyses, to determine predictive variables for the dichotomous outcomes of PCP and mortality, were performed using STATA (version 10.0, Statcorp, Texas, USA). Model variables were selected if they were associated with the outcome of interest on univariate analysis and according to biological plausibility. Variables found to be significant when analysed jointly were included in the final model. Weight- for- age and height- for- age $\mathrm{Z}$ (or standard deviation) scores were calculated using the Microsoft Office Excel (Microsoft Corporation 2003) addin ImsGrowth Program (version 2.12, Medical Research Council UK, 2002 - 2005) (15). The WHO categorises weight- for age and height- for age scores $\leq 2$ as representing moderate under-nutrition and scores $\leq 3$ representing malnutrition [16]. A 95\% significance level was chosen.

\section{Results}

Two hundred and two children [92 (45.5\%) male] were enrolled with a median (interquartile range, IQR) age of $3.2(2.1$ - 4.6) months. HIV results were available for 200 children; 124 (61.4\%) were HIV infected; 34 (16.8\%) were HIV exposed but uninfected and 42 (20.8\%) were HIV unexposed. Seventy of the HIV exposed or infected children (44.3\%) had been in the Prevention of Mother to Child Transmission (PMTCT) program, but only 29 (18.4\%) were receiving cotrimoxazole prophylaxis. Five (4\%) HIV infected children were on HAART; 72 (58\%) were started on HAART during hospitalization, at a median (IQR) of 10 (7 - 14.5) days after admission. One 
hundred and nine (54\%) patients received gancyclovir for presumed or proven CMV infection.

Most children were under- nourished with median (IQR) weight- for age and height- for age $\mathrm{Z}$ scores of -2.5 ( -4.3 to -1.5$)$ and -2.3 ( -3.9 to -0.9$)$ respectively. The most common presenting features were cough $(85.1 \%)$, vomiting $(31.2 \%)$, diarrhoea $(21.8 \%)$, or poor feeding $(24.3 \%)$; these did not differ by HIV status.

\section{PCP}

Pneumocystis jirovecii was detected in 43 (21.3\%) children by IF and/or Grocott staining and in 109 (54.0\%) children using PCR $(p<0.0001)$ on 107 induced sputum and 97 BAL specimens. No child was positive by IF and negative by PCR. Eighty- seven children (79.8\%) with PCP were HIV infected (Table 1). Risk factors amongst the 21 HIV uninfected children with PCP included malnutrition in 12 (57.1\%) children, HIV exposure in 5 (23.8\%); a history of prematurity in 5 (23.8\%); congenital cardiac disease in 2 (9.5\%); and primary immune deficiency and post- transplant immunosuppression in one child each. Clinical features distinguishing children with PCP from those without PCP were absence of fever, higher respiratory rate and lower oxygen saturation on admission (Table 1).

\section{Co-infection}

Co-infection with CMV was common in children with PCP. The prevalence of CMV pneumonia or viraemia was higher in children with PCP compared to those without PCP (Table 2). In contrast other respiratory viruses were more commonly identified in children without PCP (Table 2). There was no difference in the rate of bacteraemia or culture confirmed tuberculosis between the two groups.

\section{Predictive factors for PCP}

$\mathrm{LDH}$ and $\mathrm{SpO}_{2}$ were not included in the multiple regression analyses due to missing data.In the final model cotrimoxazole prophylaxis was found to be protective for PCP; whilst HIV infection, CMV viraemia, lack of fever and tachypnoea were associated with PCP (Table 3).

\section{Outcome}

There was no difference between children with PCP compared to those without PCP in terms of PICU admission; ventilation requirements and duration; or length of hospital and PICU stay. The in-hospital mortality was 35 (32.1\%) in children with PCP compared to 16 (17.2\%) in those without PCP (relative risk 1.87; 95\% CI 1.11 - 3.15;

Table 1 Univariate comparison between PCP positive and negative patients by presenting clinical and laboratory data

\begin{tabular}{|c|c|c|c|}
\hline \multirow[t]{2}{*}{ Variable } & \multirow{2}{*}{$\begin{array}{c}\text { PCP positive } \\
n=109\end{array}$} & \multirow{2}{*}{$\begin{array}{c}\text { PCP negative } \\
n=93\end{array}$} & \multirow[t]{2}{*}{$p$} \\
\hline & & & \\
\hline \multicolumn{4}{|l|}{ Presenting symptoms $\mathbf{n}(\%)$} \\
\hline Cough & $94(86.2)$ & $78(83.9)$ & 0.6 \\
\hline Fever & $30(27.5)$ & $47(50.5)$ & 0.0008 \\
\hline Poor feeding & $28(25.7)$ & $21(22.6)$ & 0.6 \\
\hline \multicolumn{4}{|l|}{ Patient characteristics } \\
\hline Gender M:F & $47: 62$ & $45: 48$ & 0.5 \\
\hline Age (Months) & $3.4(2.7-4.0)$ & $2.2(1.3-6.8)$ & 0.03 \\
\hline HIV infected n (\%) & $87(79.8)$ & $37(39.8)$ & $<0.0001$ \\
\hline HIV exposed, uninfected & $5(4.6)$ & $29(31.2)$ & $<0.0001$ \\
\hline Weight for age $Z$ score & $-2.9(-4.6--1.6)$ & $-2.4(-3.9--1.36)$ & 0.08 \\
\hline Height for age Z score & $-2.4(-4.5--0.9)$ & $-2.3(-3.2--0.9)$ & 0.24 \\
\hline Duration of symptoms (days) & $3.0(2.0-7.0)$ & $3.0(1.0-7.0)$ & 0.66 \\
\hline \multicolumn{4}{|l|}{ Admission signs } \\
\hline Respiratory rate on admission (breaths per minute) & $70.0(60.0-80.0)$ & $60.0(50-70)$ & 0.0002 \\
\hline Subcostal recessions n (\%) & $107(98.2)$ & $83(89.2)$ & 0.8 \\
\hline $\mathrm{SpO}_{2}(\%)$ in room air $(n=146)$ & $77.0(65.5-84.0)$ & $87.5(75.0-92.0)$ & $<0.0001$ \\
\hline \multicolumn{4}{|l|}{ Laboratory investigations } \\
\hline \multirow[t]{2}{*}{ CD4\% in HIV infected children } & $17.1(9.9-29.7)$ & $21.0(14.7-29.7)$ & 0.12 \\
\hline & $\mathrm{n}=80$ & $\mathrm{n}=35$ & \\
\hline \multirow[t]{2}{*}{ Lactate dehydrogenase (u/l) } & $710.5(534.5-1067.0)$ & $350.0(238.0-610.0)$ & $<0.0001$ \\
\hline & $n=57$ & $n=35$ & \\
\hline
\end{tabular}

Continuous data are median (interquartile range). 
Table 2 Co-infection in children with and without PCP

\begin{tabular}{|c|c|c|c|}
\hline \multirow[t]{2}{*}{ Variable } & \multirow{2}{*}{$\frac{\text { PCP positive }}{n=109}$} & \multirow{2}{*}{$\frac{\text { PCP negative }}{n=93}$} & \multirow[t]{2}{*}{$p$} \\
\hline & & & \\
\hline $\begin{array}{l}\text { Cytomegalovirus (CMV) blood } \\
\text { PCR positive }\end{array}$ & $81(74.3)$ & $43(46.2)$ & $<0.0001$ \\
\hline CMV pneumonia & $34(31.2)$ & $11(11.8)$ & 0.001 \\
\hline M. tuberculosis culture positive & $1(0.9)$ & $4(4.3)$ & 0.3 \\
\hline Viruses other than CMV & $29(26.6)$ & $41(44)$ & 0.009 \\
\hline Bacteraemia & $7(6.4)$ & $13(14.0)$ & 0.12 \\
\hline Staphylococcus aureus & 1 & 1 & \\
\hline Escherichia coli & 1 & 1 & \\
\hline Klebsiella pneumoniae & 1 & 1 & \\
\hline Enterococcus faecalis & 1 & 1 & \\
\hline Streptococcus pneumoniae & 0 & 1 & \\
\hline Pseudomonas aeruginosa & 0 & 3 & \\
\hline Non-typhoidal Salmonella spp. & 0 & 1 & \\
\hline
\end{tabular}

Numbers are $\mathrm{n}(\%)$.

$p=0.02)$. Multiple regression controlling for age, HIV infection, PCP and cotrimoxazole prophylaxis showed that only HIV infection was predictive of mortality (OR 3.7, $95 \%$ CI $1.5-9.0 ; p=0.004)$. In a separate model of 115 HIV infected children with complete data, only CD4 count $<15 \%$ was significantly associated with mortality (OR 3.6, 95\% CI 1.4 - 9.0; $p=0.006$ ) (Table 4). None of the five HIV exposed uninfected infants with PCP died.

\section{Discussion}

PCP was diagnosed in more than half of children hospitalised with hypoxic pneumonia using molecular techniques, more than double that diagnosed by IF or Grocott staining on the same respiratory samples [2]. The incidence of PCP reported in prior studies based on IF staining of respiratory secretions may therefore be a large underestimate [1,2,6-10,29-32]. The study indicates that PCP in HIV-infected infants is even more of a concern than was previously recognised, and emphasises the need to strengthen paediatric HIV programs including early use of cotrimoxazole prophylaxis and HAART according to current global guidelines [29,33].

Table 3 Logistic regression model of predictive factors for PCP

\begin{tabular}{lccc}
\hline Variable & Adjusted odds ratio & $\mathbf{9 5 \%} \mathbf{C l}$ & $\boldsymbol{p}$ \\
\hline Cotrimoxazole prophylaxis & 0.2 & $0.07-0.5$ & 0.002 \\
HIV infection & 8.2 & $3.8-17.8$ & $<0.0001$ \\
CMV blood PCR positivity & 2.4 & $1.2-5.0$ & 0.02 \\
Fever & 0.3 & $0.4-0.6$ & 0.001 \\
Respiratory rate $>60$ & 3.5 & $1.7-7.0$ & 0.0005 \\
breaths per minute & & &
\end{tabular}

CMV-cytomegalovirus; $\mathrm{Cl}$ - confidence interval. Lactate dehydrogenase and oxygen saturation were not included due to missing data.
Table 4 Logistic regression model for predictors of outcome in HIV infected children $(n=115)$

\begin{tabular}{lccc}
\hline & Adjusted odds ratio & $\mathbf{9 5 \%} \mathbf{C l}$ & $\boldsymbol{p}$ \\
\hline Age (months) & 1.00 & $0.97-1.04$ & 0.9 \\
Gender & 0.61 & $0.23-1.62$ & 0.3 \\
Weight for age (\%) & 0.97 & $0.78-1.20$ & 0.8 \\
Cotrimoxazole prophylaxis & 1.51 & $0.47-4.83$ & 0.5 \\
CD4 $<15 \%$ & 3.59 & $1.43-9.01$ & 0.006 \\
PCP & 1.12 & $0.36-3.52$ & 0.8 \\
CMV pneumonia & 1.92 & $0.74-4.92$ & 0.2 \\
\hline
\end{tabular}

PCP pneumocystis pneumonia; CMV cytomegalovirus.

Cotrimoxazole prophylaxis and HAART had been instituted in only a minority of eligible children despite the free availability of HAART and PMTCT programs in this area of South Africa. Reassuringly, cotrimoxazole prophylaxis was found to be highly effective for preventing PCP, supporting the widespread use of this cost-effective intervention $[29,34,35]$. Although this study was not designed to investigate implementation of national policies for paediatric HIV or adherence to HAART or cotrimoxazole, the results indicate that the HIV program is still not functioning appropriately, with potentially devastating consequences. Further research to investigate the underlying reasons for failure of the PMTCT and HAART programs in this setting is needed.

The in- hospital case fatality rate for children with PCP of $32 \%$ is within the range reported in other African studies [1,9-11], and is also similar to that reported eight years previously from the same study site [9].

A minority of HIV uninfected children also developed PCP. Consistent with prior reports, a number of risk factors were identified $[1,9,11,36]$ including malnutrition and HIV exposure $[4,12,14,15]$. HIV exposed infants may be at increased risk of PCP due to impaired immunity, exposure to $P$. jirovecii from an HIV infected mother or adult, or poor protection from maternal antibodies [4,12,15,37,38]. All HIV exposed but uninfected infants with proven PCP survived, consistent with previous reports of better outcome in HIV uninfected compared to HIV infected infants [16]. With strengthening of PMTCT programs, HIV exposed but uninfected infants are an increasingly important group who may be at risk for PCP. The use of cotrimoxazole prophylaxis in this group deserves further consideration given the increasing number of case reports of PCP in HIV-exposed uninfected infants and this growing population [4,39].

Clinical and laboratory measures associated with PCP were similar to previous reports [2,32]. Although elevated LDH may be a non-specific marker of lung injury [40], these results suggest that there should be a high index of suspicion of PCP in those children with raised 
LDH admitted to hospital with severe pneumonia, particularly when there are other known risk factors for PCP.

As expected, co-infection with $P$. jirovecii and other pathogens, particularly viruses, was common $[2-4,6,41,42]$. Similar to previous studies, CMV coinfection occurred most frequently, in a third of children with PCP $[4,6,7,43,44]$. This may also reflect severe immunosuppression as CMV pneumonia has been associated with moderate or severe immunosuppression in HIV-infected infants [4-6,43-46].

Limitations of this study include lack of a control group. Several adult studies have reported carriage of $P$. jirovecii as detected by a positive PCR on respiratory specimens $[22,47,48]$, however, positive PCR results in our study are unlikely to represent colonisation given the presentation of severe pneumonia, the young age of infants and the protective effect of cotrimoxazole prophylaxis [23]. We were unable to use response to treatment as a means of confirming PCR diagnosis as all children were treated for presumptive PCP based on clinical signs. The lack of a gold standard for PCP diagnosis makes testing of any new diagnostic modality challenging, especially as the organism cannot be easily cultured. This was a single- centre study of a selected population admitted to a tertiary hospital; therefore results may not be generalisable to children from different geographical areas and with different clinical disease spectra. Further studies of PCR based diagnosis in children with non-HIV immunosuppression are needed.

\section{Conclusions}

PCP remains a common cause of severe hypoxic pneumonia and is associated with high mortality in HIV-infected African infants. New molecular diagnost ic methods indicate that the burden of PCP in this populat ion has been under -est imated in the past.

\section{Competing interests}

The authors declare that they have no competing interests.

\section{Authors' contributions}

BM recruited patients, acquired and analysed data, and drafted the manuscript. $\mathrm{HZ}$ was responsible for study conception and design, clinical supervision and obtaining funding. AW was the laboratory supervisor, contributed to the study design and obtained funding. MZ recruited patients and acquired data. CS performed the molecular investigations. All authors contributed to the final manuscript and have read and approved of it.

\footnotetext{
Acknowledgements

This research was supported by an NHLS Research Trust grant; the National Research Foundation, South Africa; ASTRA-Zeneca Respiratory Award from the South African Thoracic Society and the Medical Research Council of Southern Africa. We thank Louise LeSai for her assistance with enrolling patients.
}

\section{Author details}

${ }^{1}$ Department of Paediatics and Child Health, Red Cross War Memorial Children's Hospital (RCWMCH), University of Cape Town, 5th Floor Institute of Child Health Building, Klipfontein Road, Rondebosch 7700, Cape Town, South Africa. ${ }^{2}$ Division of Medical Microbiology, National Health Laboratory Services, University of Cape Town, Cape Town, South Africa.
Received: 10 April 2012 Accepted: 3 January 2014

Published: 10 January 2014

\section{References}

1. Graham SM, Mtitimila El, Kamanga HS, Walsh AL, Hart CA, Molyneux ME: Clinical presentation and outcome of Pneumocystis carinii pneumonia in Malawian children. Lancet 2000, 355:369-373.

2. Morrow BM, Hsaio NY, Zampoli M, Whitelaw A, Zar HJ: Pneumocystis Pneumonia in South African Children With and Without Human Immunodeficiency Virus Infection in the Era of Highly Active Antiretroviral Therapy. Pediatr Infect Dis J 2010, 29:535-539.

3. Zar HJ, Apolles P, Argent A, Klein M, Burgess J, Hanslo D, et al: The etiology and outcome of pneumonia in human immunodeficiency virus-infected children admitted to intensive care in a developing country. Pediatr Crit Care Med 2001, 2:108-112.

4. McNally LM, Jeena PM, Gajee K, Thula SA, Sturm AW, Cassol S, et al: Effect of age, polymicrobial disease, and maternal HIV status on treatment response and cause of severe pneumonia in South African children: a prospective descriptive study. Lancet 2007, 369:1440-1451.

5. Ansari NA, Kombe AH, Kenyon TA, Mazhani L, Binkin N, Tappero JW, et al: Pathology and causes of death in a series of human immunodeficiency virus-positive and -negative pediatric referral hospital admissions in Botswana. Pediatr Infect Dis J 2003, 22:43-47.

6. Chintu C, Mudenda V, Lucas S, Nunn A, Lishimpi K, Maswahu D, et al: Lung diseases at necropsy in African children dying from respiratory illnesses: a descriptive necropsy study. Lancet 2002, 360:985-990.

7. Jeena PM, Coovadia HM, Chrystal V: Pneumocystis carinii and cytomegalovirus infections in severely ill, HIV-infected African infants. Ann Trop Paediatr 1996, 16:361-368.

8. Nathoo KJ, Gondo M, Gwanzura L, Mhlanga BR, Mavetera T, Mason PR: Fatal Pneumocystis carinii pneumonia in HIV-seropositive infants in Harare, Zimbabwe. Trans R Soc Trop Med Hyg 2001, 95:37-39.

9. Zar HJ, Dechaboon A, Hanslo D, Apolles P, Magnus KG, Hussey G: Pneumocystis carinii pneumonia in South African children infected with human immunodeficiency virus. Pediatr Infect Dis J 2000, 19:603-607.

10. Ruffini DD, Madhi SA: The high burden of Pneumocystis carinii pneumonia in African HIV-1-infected children hospitalized for severe pneumonia. AIDS 2002, 16:105-112.

11. Madhi SA, Cutland C, Ismail K, O'Reilly C, Mancha A, Klugman KP: Ineffectiveness of trimethoprim-sulfamethoxazole prophylaxis and the importance of bacterial and viral coinfections in African children with Pneumocystis carinii pneumonia. Clin Infect Dis 2002, 35:1120-1126.

12. McNally LM, Jeena PM, Lalloo U, Nyamande K, Gajee K, Sturm AW, et al: Probable mother to infant transmission of Pneumocystis jiroveci from an HIV-infected woman to her HIV-uninfected infant. AIDS 2005, 19:1548-1549.

13. Madhi SA, Zar HJ, Saloojee H, Gray GE: Co-trimoxazole prophylaxis in African children with HIV-1. Lancet 2005, 365:749-50.

14. Russian DA, Levine SJ: Pneumocystis carinii pneumonia in patients without HIV infection. Am J Med Sci 2001, 321:56-65.

15. Slogrove AL, Cotton MF, Esser MM: Severe infections in HIV-exposed uninfected infants: clinical evidence of immunodeficiency. J Trop Pediatr 2010, 56:75-81.

16. Jeena PM, Bobat B, Thula SA, Adhikari M: Children with Pneumocystis jiroveci pneumonia and acute hypoxaemic respiratory failure admitted to a PICU, Durban. South Africa. Arch Dis Child 2008, 93:545.

17. Gona P, Van Dyke RB, Williams PL, Dankner WM, Chernoff MC, Nachman SA, et al: Incidence of opportunistic and other infections in HIV-infected children in the HAART era. JAMA 2006, 296:292-300.

18. Chiappini E, Galli L, Tovo PA, Gabiano C, Lisi C, Gattinara GC, et al: Changing patterns of clinical events in perinatally HIV-1-infected children during the era of HAART. AIDS 2007, 21:1607-1615.

19. Nesheim SR, Kapogiannis BG, Soe MM, Sullivan KM, Abrams E, Farley J, et al: Trends in opportunistic infections in the pre- and post-highly active antiretroviral therapy eras among HIV-infected children in the Perinatal AIDS Collaborative Transmission Study, 1986-2004. Pediatrics 2007, 120:100-109.

20. Samuel CM, Whitelaw A, Corcoran C, Morrow B, Hsiao N, Zampoli M, et al: Improved detection of Pneumocystis jirovecii in upper and lower respiratory tract specimens from children with suspected pneumocystis pneumonia using real-time PCR: a prospective study. BMC Infect Dis 2011, 11:329. 
21. Tia T, Putaporntip C, Kosuwin R, Kongpolprom N, Kawkitinarong K, Jongwutiwes S: A highly sensitive novel PCR assay for detection of Pneumocystis jirovecii DNA in bronchoalveloar lavage specimens from immunocompromised patients. Clin Microbiol Infect 2011. doi: 10.1186/1471-2334-11-329.

22. Morris A, Wei K, Afshar K, Huang L: Epidemiology and clinical significance of pneumocystis colonization. J Infect Dis 2008, 197:10-17.

23. Carmona EM, Limper AH: Update on the diagnosis and treatment of Pneumocystis pneumonia. Ther Adv Respir Dis 2011, 5:41-59.

24. Oren I, Hardak E, Finkelstein R, Yigla M, Sprecher H: Polymerase chain reaction-based detection of Pneumocystis jirovecii in bronchoalveolar lavage fluid for the diagnosis of pneumocystis pneumonia. Am J Med Sci 2011, 342:182-185.

25. Zar HJ, Tannenbaum E, Hanslo D, Hussey G: Sputum induction as a diagnostic tool for community-acquired pneumonia in infants and young children from a high HIV prevalence area. Pediatr Pulmonol 2003, 36:58-62.

26. Morrow B, Futter $M$, Argent A: A simple method of reducing complications of pediatric nonbronchoscopic bronchoalveolar lavage. Pediatr Pulmonol 2004, 38:217-221.

27. Zar HJ, Jeena P, Argent A, Gie R, Madhi SA, Working Groups of the Paediatric Assembly of the South African Thoracic Society: Diagnosis and management of community-acquired pneumonia in childhood-South African Thoracic Society Guidelines. S Afr Med J 2005, 95:977-81. 984-90.

28. Southern African HIV Clinicians Society: Guidelines for: Antiretroviral Therapy in Children. 2005. www.sahivsoc.org/upload/documents/guidelines_nov_2005.pdf.

29. World Health Organisation: WHO Recommendations on the Management of Diarrhoea and Pneumonia in HIV-infected Infants and Children: Integrated Management of Childhood IIIness (IMCI). 2010. www.unicef.org/aids/files/ hiv_diarrhoea_and_pneumonia.pdf.

30. Lucas SB, Peacock CS, Hounnou A, Brattegaard K, Koffi K, Honde M, et al: Disease in children infected with HIV in Abidjan, Cote d'Ivoire. BMJ 1996, 312:335-338.

31. Ikeogu MO, Wolf B, Mathe S: Pulmonary manifestations in HIV seropositivity and malnutrition in Zimbabwe. Arch Dis Child 1997, 76:124-128.

32. Graham SM, Mankhambo L, Phiri A, Kaunda S, Chikaonda T, Mukaka M, et al: Impact of human immunodeficiency virus infection on the etiology and outcome of severe pneumonia in Malawian children. Pediatr Infect Dis $J$ 2011, 30:33-38.

33. World Health Organisation: WHO Guidelines for Cotrimoxazole Prophylaxis for HIV-related Infections among Children, Adolescents and Adults in Resourcelimited Settings. Recommendations for a Public Health Approach. 2006:1-68. www.who.int/hiv/pub/guidelines/ctxguidelines.pdf.

34. Grimwade K, Swingler GH: Cotrimoxazole prophylaxis for opportunistic infections in children with HIV infection. Cochrane Database Syst Rev 2006, 1, CD003508.

35. Chintu C, Bhat GJ, Walker AS, Mulenga V, Sinyinza F, Lishimpi K, et al: Co-trimoxazole as prophylaxis against opportunistic infections in HIV-infected Zambian children (CHAP): a double-blind randomised placebo-controlled trial. Lancet 2004, 364:1865-1871.

36. Fatti GL, Zar HJ, Swingler GH: Clinical indicators of Pneumocystis jiroveci pneumonia (PCP) in South African children infected with the human immunodeficiency virus. Int J Infect Dis 2006, 10:282-285.

37. de Moraes-Pinto MI, Almeida AC, Kenj G, Filqueiras TE, Tobias W, Santos AM, et al: Placental transfer and maternally acquired neonatal lgG immunity in human immunodeficiency virus infection. J Infect Dis 1996, 173:1077-1084.

38. Kuhn L, Kasonde P, Sinkala M, Kankasa C, Semrau K, Scott N, et al: Does severity of HIV disease in HIV-infected mothers affect mortality and morbidity among their uninfected infants? Clin Infect Dis 2005, 41:1654-1661.

39. Coutsoudis A, Coovadia HM, Kindra G: Time for new recommendations on cotrimoxazole prophylaxis for HIV-exposed infants in developing countries? Bull World Health Organ 2010, 88:949-950.

40. Opravil M, Marincek B, Fuchs WA, Weber R, Speich R, Battegay M, et al: Shortcomings of chest radiography in detecting Pneumocystis carinii pneumonia. J Acquir Immune Defic Syndr 1994, 7:39-45.

41. Madhi SA, Petersen K, Madhi A, Khoosal M, Klugman KP: Increased disease burden and antibiotic resistance of bacteria causing severe communityacquired lower respiratory tract infections in human immunodeficiency virus type 1-infected children. Clin Infect Dis 2000, 31:170-176.

42. Graham SM: HIV-related pulmonary disorders: practice issues. Ann Trop Paediatr 2007, 27:243-252.
43. Zampoli M, Morrow B, Hsiao NY, Whitelaw A, Zar HJ: Prevalence and outcome of cytomegalovirus-associated pneumonia in relation to human immunodeficiency virus infection. Pediatr Infect Dis J 2011, 30:413-417.

44. Williams AJ, Duong T, McNally LM, Tookey PA, Masters J, Miller R, et al: Pneumocystis carinii pneumonia and cytomegalovirus infection in children with vertically acquired HIV infection. AIDS 2001, 15:335-339.

45. Kovacs A, Schluchter M, Easley K, Demmler G, Shearer W, La Russa P, et al: Cytomegalovirus infection and HIV-1 disease progression in infants born to HIV-1-infected women. Pediatric Pulmonary and Cardiovascular Complications of Vertically Transmitted HIV Infection Study Group. N Engl J Med 1999, 341:77-84.

46. Nigro G, Krzysztofiak A, Gattinara GC, Mango T, Mazzocco M, Porcaro MA, et al: Rapid progression of HIV disease in children with cytomegalovirus DNAemia. AIDS 1996, 10:1127-1133.

47. Olsson $M$, Stralin $K$, Holmberg H: Clinical significance of nested polymerase chain reaction and immunofluorescence for detection of Pneumocystis carinii pneumonia. Clin Microbiol Infect 2001, 7:492-497.

48. Gutierrez S, Morilla R, Leon JA, Martin-Garrido I, Rivero L, Friaza V, et al: High prevalence of Pneumocystis jiroveci colonization among young HIV-infected patients. J Adolesc Health 2011, 48:103-105.

doi:10.1186/1756-0500-7-26

Cite this article as: Morrow et al:: Pneumocystis pneumonia in South African children diagnosed by molecular methods. BMC Research Notes 2014 7:26.

\section{Submit your next manuscript to BioMed Central and take full advantage of:}

- Convenient online submission

- Thorough peer review

- No space constraints or color figure charges

- Immediate publication on acceptance

- Inclusion in PubMed, CAS, Scopus and Google Scholar

- Research which is freely available for redistribution 